Volume 3, Issue 2, pages 215-224

\title{
Heat Transfer Characteristic on Wing Pairs Vortex Generator using 3D Simulation of Computational Fluid Dynamic
}

\author{
Petrus Setyo Prabowo ${ }^{1}$, Stefan Mardikus ${ }^{2, *}$, \\ Ewaldus Credo Eukharisto ${ }^{2}$ \\ ${ }^{1}$ Department of Electrical Engineering, Sanata Dharma University, \\ Paingan, Maguwoharjo, Depok, Sleman, Yogyakarta 55282, Indonesia \\ ${ }^{2}$ Department of Mechanical Engineering, Sanata Dharma University, \\ Paingan, Maguwoharjo, Depok, Sleman, Yogyakarta 55282, Indonesia \\ *Corresponding Author: stefan@usd.ac.id
}

(Received 08-11-2021; Revised 07-12-2021; Accepted 07-12-2021)

\begin{abstract}
Vortex generators are addition surface that can increase heat transfer area and change the fluid flow characteristics of the working fluid to increase heat transfer coefficient. The use of vortex generators produces longitudinal vortices that can increase the heat transfer performance because of the low pressure behind vortex generators. This investigation used delta winglet vortex generator that was combined with rectangular vortex generator to Reynold numbers ranging 6.000 to 10.000 . The parameters of Nusselt number, friction factor, velocity vector and temperature distribution will be evaluated.
\end{abstract}

Keywords: Parallelogram winglet vortex generator, heat exchanger, heat transfer performance 


\section{International Journal of Applied Sciences and Smart Technologies}

Volume 3, Issue 2, pages 215-224

p-ISSN 2655-8564, e-ISSN 2685-9432

\section{Introduction}

Heat exchanger is one of various important components in the industries. Chemical industry, power plants, food factories hospitals, and super computers are using heat exchanger for their daily operation. Heat exchanger is used to transfer heat such as cooling system in super computers, boilers in power plants, evaporators to dry food at food factories, hot and cold piping system in hospitals and separator in chemical industries. One type of heat exchangers that is used most in the operation of those industries is circular tube heat exchanger.

Circular tube heat exchanger performance is affected by some parameters. Heat transfer area and fluid flow characteristics are two parameters that have great effect on heat exchanger performance. The wider the heat transfer area, the higher the heat transfer rate of heat exchanger. The addition of heat transfer area can make some adjustments to the flow characteristics of the working fluid based on the method. The method that can increase heat transfer area and change the fluid flow characteristics is the use of vortex generators.

Vortex generators are added surface that can increase heat transfer area and change the fluid flow characteristics of the working fluid to increase heat transfer performance. The use of vortex generators produces longitudinal vortices that can increase the heat transfer performance. Longitudinal vortices shapes because of the low pressure behind vortex generators. Low pressure region makes the working fluid in the middle of the flow changes its course to the side and from the side to the middle. Previous researches show that the use of vortex generators can increase heat transfer performance [1].

Deshmukh and Vedula, 2014 shows that circular tube heat exchanger using curved delta winglet vortex generator in the inner side has higher heat transfer performance compared with plain circular tube. Using the variations of Reynolds number ranging from 10.000 to 45.000 , the use of curved delta winglet vortex generator can increase Nusselt number from 1.3 to 5.0 [2]. Islam and Kharoua, 2018 studied thermal performance and flow behaviour of winglet vortex generators in circular tube using experimental method. Attack angle of $0^{\circ}, 15^{\circ}, 30^{\circ}, 45^{\circ}$, blockage ratio of 0.1, 0.2, 0.3, row values of $4,8,12$, and relative pitch ratios of $4.8,2.4,1.6$ were investigated using 


\section{International Journal of Applied Sciences and Smart Technologies}

Volume 3, Issue 2, pages 215-224

p-ISSN 2655-8564, e-ISSN 2685-9432

Reynolds number of 6.000 to 33.000. The result shows the decrease of Nusselt number with pitch row but increase with attack angle and blockage ratio [3]. Liu et al., 2018 numerically and experimentally studied heat transfer performance on circular tube heat exchanger enhanced with rectangular winglet vortex generators [4]. Reynolds number ranging from 5.000 to 17.000 was used to investigate the effect of rectangular winglet vortex generators in circular tube heat exchanger using slant angle variations of $10^{\circ}$, $20^{\circ}, 30^{\circ}$, and $35^{\circ}$. The result shows the increase of Nussselt number from 1.15 to 2.49 and friction factor from 2.09 to 12.32. Modhi and Rathod, 2019 compared the use of sinusoidal wavy and elliptical curved rectangular winglet vortex generators using $2 \mathrm{D}$ numerical method. Reynolds number of 400 to 1000 was used to study heat transfer enhancement and pressure drop varying in wavy-up, wavy-down, curved-up, and curved-down with plain rectangular winglet vortex generators as the baseline. The result shows the increase of heat transfer performance with moderate pressure drop [5]. Zhai et al., 2019 did a research of heat transfer augmentation on circular tube using delta winglet pairs vortex generator. Reynold number ranging from 5.000 to 25.000 was used to study heat transfer enhancement characteristics using the variations angle of attack $10^{\circ}, 20^{\circ}, 30^{\circ}, 40^{\circ}$, height $5 \mathrm{~mm}, 7.5 \mathrm{~mm}, 10 \mathrm{~mm}$, and space $10 \mathrm{~mm}, 15 \mathrm{~mm}, 20 \mathrm{~mm}$. Experiment result shows the application of delta winglet pairs vortex generators can increase Nusselt number up to $75 \%$ compare with plain circular tube [6]. Sun et al., 2020 studied the effect of rectangular winglet vortex generators in circular tube heat exchanger using some parameter variations. Those variations are the amount of vortex generator deployed $4,6,8$, height ratio $0.05,0.1,0.2$, and pitch ratio $1.57,3.14,4.71$. The result shows the increase of Nusselt number by 1.15 to 2.23 while the friction factor 1.46 to 11.63 [7]. Pourhedajat et al., 2020 numerically studied the use of triangular winglet vortex generators in circular tube. Longitudinal and latitudinal variations were used in that study. The result shows the smaller the longitudinal pitch the higher the heat transfer rate. The application of latitudinal pitch variations from $0 \mathrm{~mm}$ to $40 \mathrm{~mm}$ shows $20 \mathrm{~mm}$ latitudinal pitch resulting in the highest heat transfer enhancement [8]. Zang et al., 2020 investigated heat transfer performance of rectangular winglet vortex generators applied in circular tube heat exchanger. Parallel and v-shaped configuration was used in that study with the variations of attack angle and length ratio. The use of parallel 


\section{International Journal of Applied Sciences and Smart Technologies}

Volume 3, Issue 2, pages 215-224

p-ISSN 2655-8564, e-ISSN 2685-9432

configuration results in the increase of heat transfer rate by $54 \%$ to $188 \%$ and flow resistance by $152 \%$ to $568 \%$. The use of v-shaped configuration results in the increase of heat transfer rate by $60 \%$ to $118 \%$ and flow resistance by $141 \%$ to $644 \%$ [9].

Based on those previous studies that are reviewed above, there are still many improvements that can be done by researchers. This study focus on heat transfer enhancement using a novel type of vortex generators, parallelogram winglet vortex generator. Parallelogram winglet vortex generator is a new type of vortex generators that is inspired by combining the characteristics of delta winglet vortex generator and rectangular winglet vortex generator.

Parallelogram winglet vortex generator has the shape of delta winglet vortex generator that is combined with rectangular vortex generator. Heat transfer enhancement of circular tube heat exchanger using parallelogram winglet vortex generators was studied numerically with plain circular tube heat exchanger as the baseline. Reynolds number ranging from 6.000 to 10.000 was used in this study to identify the heat transfer performance with the variations of parallelogram vortex generators lean following the flow and lean against the flow configuration. Nusselt number, friction factor, velocity vector and temperature distribution were used in this research as evaluation parameters.

\section{Research Methods}

Three dimensional numerical method was carried out in this study to investigate heat transfer performance of circular tube heat exchanger embedded with parallelogram winglet vortex generators.

\subsection{Model Description}

The simulation was carried out in two different parallelogram winglet vortex generators configurations that are lean following the flow as can be seen at Figure 1, and against the flow as can be seen at Figure 2. The length of the pipe is $700 \mathrm{~mm}$ with vortex generators embedded inside the circular tube. As can be seen at Figure 3, the diameter of the tube is $50.8 \mathrm{~mm}$ with the thickness of $3 \mathrm{~mm}$. Six pairs parallelogram 


\section{International Journal of Applied Sciences and Smart Technologies}

Volume 3, Issue 2, pages 215-224

p-ISSN 2655-8564, e-ISSN 2685-9432

winglet vortex generators with the pitch of $100 \mathrm{~mm}$. Each pair composed of 4 vortex generators that was arranged at $0^{\circ}, 90^{\circ}, 180^{\circ}, 270^{\circ}$ of the cross section area. The attack angle of $0^{\circ}$ was applied to the parallelogram winglet vortex generators to investigate the most basic effect of it used in circular tube heat exchanger. The geometry of parallelogram winglet vortex generator is shown in Figure 4. The parallelogram winglet vortex generator has the short diagonal of $15 \mathrm{~mm}$ and long diagonal $30 \mathrm{~mm}$.

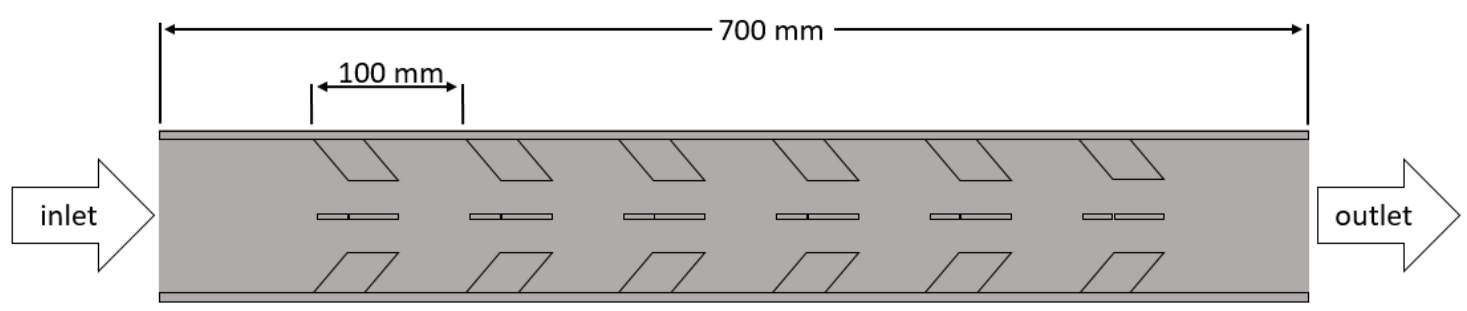

Figure 1. Lean following of the flow configuration.

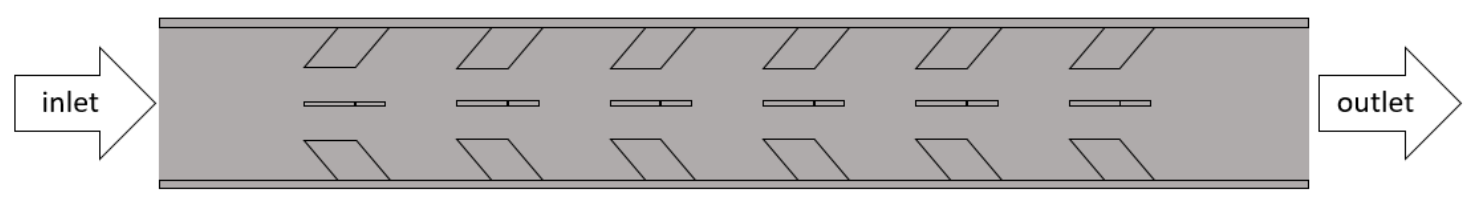

Figure 2. Lean against of the flow configuration.

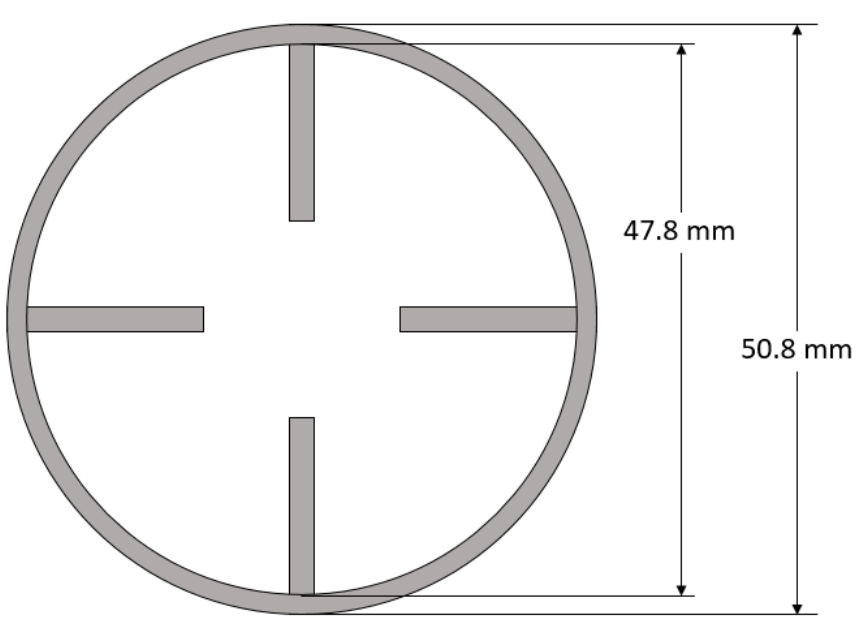

Figure 3. Cross section of the physical model. 


\section{International Journal of Applied Sciences and Smart Technologies}

Volume 3, Issue 2, pages 215-224

p-ISSN 2655-8564, e-ISSN 2685-9432

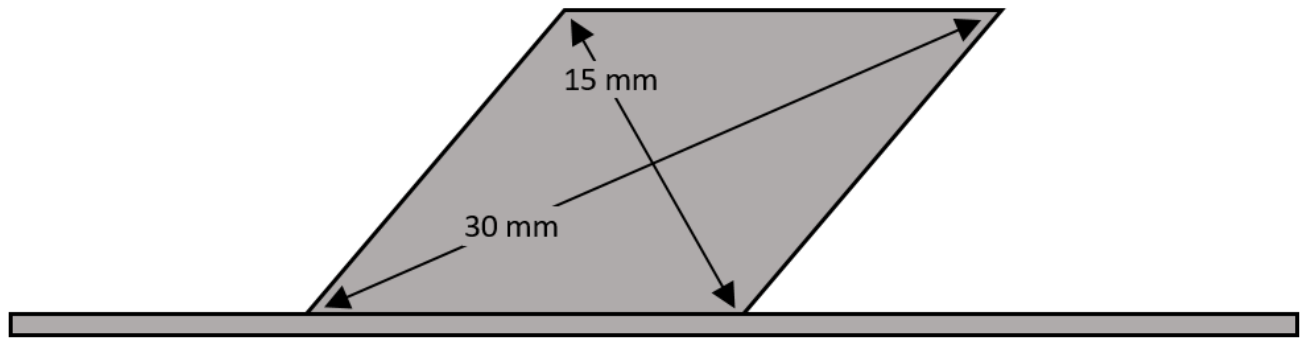

Figure 4. Cross section of the physical model of parallelogram winglet vortex generator

\subsection{Boundary Condition}

Three dimensional numerical method was carried out using Reynolds number ranging from 6.000 to 10.000 . The working fluid was assumed to be steady turbulent flow. Inlet temperature of the working fluid was $322.2 \mathrm{~K}$. The wall and the vortex generator assumed to have the same temperature of $300 \mathrm{~K}$. The working fluid used in this study was ammonia. Coupled pressure and velocity in governing equation in this study was solved using the SIMPLE algorithm. The thermal convection and the velocity was discretized by second order upwind. The residual criteria less than 10-6 was used for the energy equation and 10-4 for the other variables.

\section{Results and Discussion}

Heat transfer performance of the cases studied was evaluated using Nusselt number and thermal gradient. Figure 5 shows the Nusselt number increases with Reynolds number that is similar in the tendency of the study by Liu et al [4]. This study has overall Nusselt number higher than Liu et al [4] study due to the use of ammonia as the working fluid that is lower in thermal conductivity than water used by Liu et al study.

The Nusselt numbers in Figure 5 increase with Reynolds numbers in all cases studied. In the case of the plain circular tube the increase of Nusselt number from 6.000 to $7.000,8.000,9.000$, and 10.000 are $12.86 \%, 25.54 \%, 37.18 \%$, and $47.38 \%$. In the case of vortex generators leaned following the flow configuration the increase of Nusselt numbers are $11.34 \% 22.55 \% 33.71 \%$ and $44.79 \%$. In the case of vortex generators lean against the flow configuration the increase of Nusselt numbers are $10.72 \%, 21.61 \%, 32.44 \%$, and $43.00 \%$. Based on the data showed in this study the plain 


\section{International Journal of Applied Sciences and Smart Technologies}

Volume 3, Issue 2, pages 215-224

p-ISSN 2655-8564, e-ISSN 2685-9432

tube has the highest increase in Nusselt number with the increase of Reynolds number. It is followed by the use of vortex generators leaned following the flow and the lowest Nusselt number increase is by the used of vortex generators leaned against the flow.

Based on the use of vortex generators compare with the plain case, the vortex generators leaned following the flow configuration has the average increase of Nusselt number $5.38 \%$ with the lowest value $4.39 \%$ in the Reynolds number 9000 and the highest $7.1 \%$ in Reynolds number 6000 and the vortex generators leaned against the flow configuration has the average increase of Nusselt number 22,49\% with the lowest value $21.04 \%$ in the Reynolds number 9000 and the highest $25.36 \%$ in the Reynolds number 6000 . The use of vortex generators leaned against the flow configuration has the higher increase of Nusselt number compare with vortex generators leaned following the flow configuration with the lowest and highest value in the same Reynolds number variations. The highest increase in Nusselt number value occurred in the use of Reynolds number 6000 was caused by the contact time between the working fluid and the heat transfer surface area of the tube and the vortex generators applied [10].

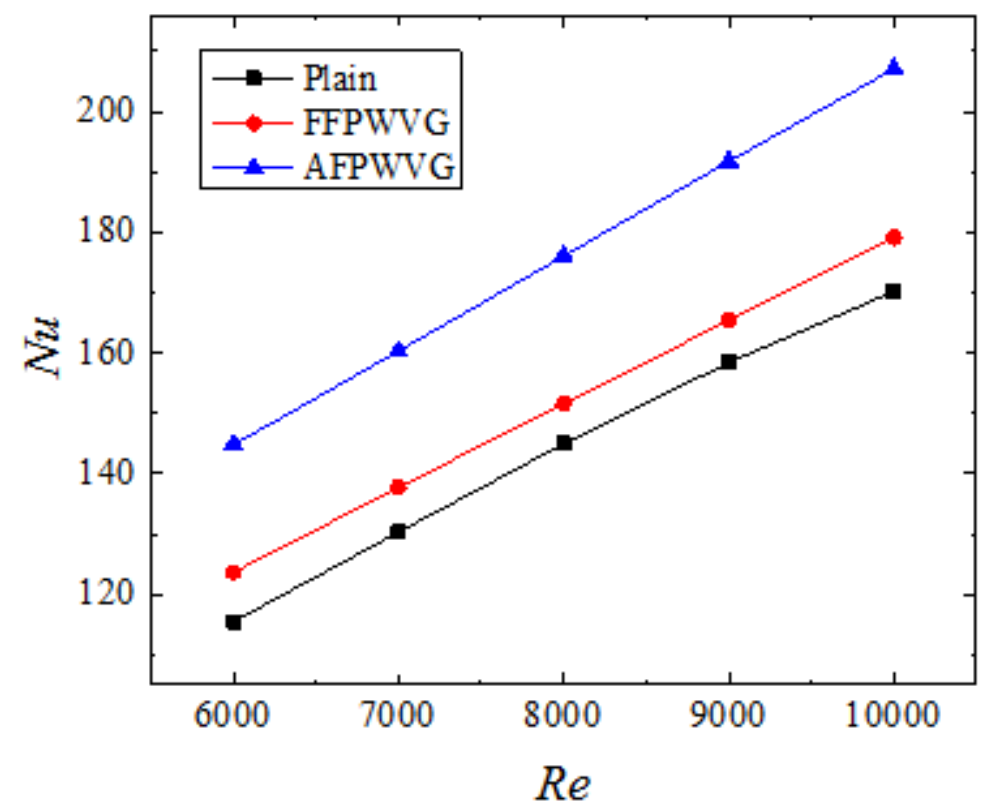

Figure 5. Reynolds number vs Nusselt number for Plain tube, leaned following the flow parallelogram winglet vortex generators arrangement and against the flow parallelogram winglet vortex generators arrangement 


\section{International Journal of Applied Sciences and Smart Technologies}

Volume 3, Issue 2, pages 215-224

p-ISSN 2655-8564, e-ISSN 2685-9432

Temperature gradient was also used in this study to understand the heat transfer phenomena occurred. Figure 6, Figure 7, and Figure 8 showed the thermal gradient of the plain tube, lean following the flow configuration, and lean against the flow configuration using Reynolds number 6000. The temperature gradient of Reynolds number 6000 was used to investigate the temperature distribution characteristic due to the highest increase of the Nusselt number. The plain case in Figure 6 showed that the working fluid temperature has a smooth pattern from the inlet to the outlet. It means that the working fluid has relatively low temperature distribution. The use of vortex generator increases the temperature distribution due to the increase of contact surface between the working fluid and tube wall [Liu et al., 2018]. The use of vortex generator in Figure 7 and Figure 8 showed the better temperature distribution compare with the plain case in Figure 6. The high temperature not only occurs in the middle stream but also near the tube wall. However, temperature distribution in the case of leaned against the flow configuration showed by Figure 8 is higher than the case of leaned following the flow configuration showed by Figure 7.
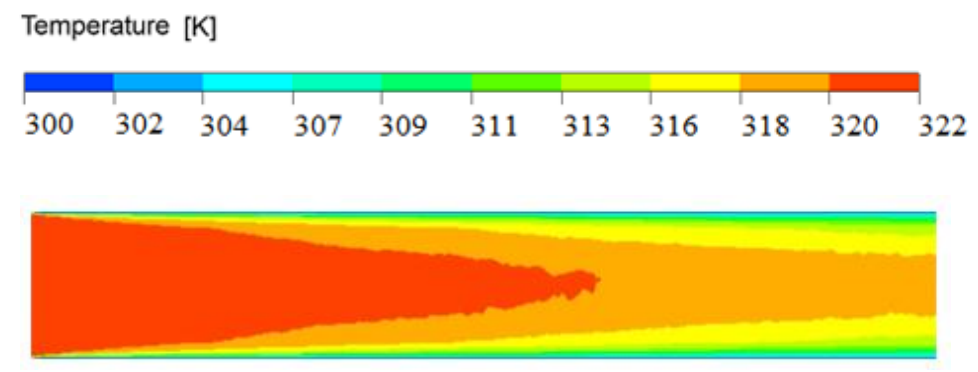

Figure 6. Temperature gradients of the plain case Re 6000

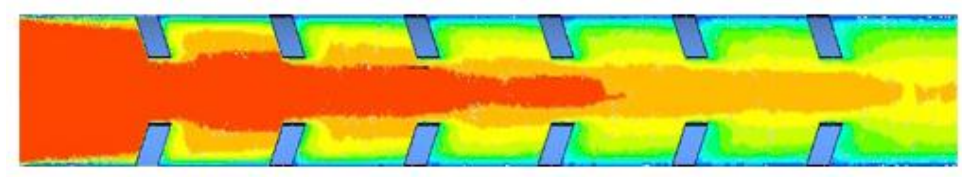

Figure 7. Temperature gradient of the leaned following the flow configuration Re 6000

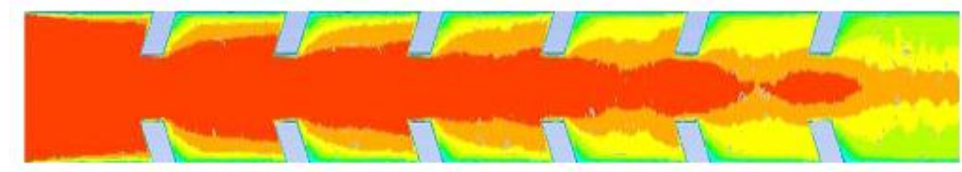

Figure 8. Temperature gradient of the leaned against the flow configuration Re 6000 


\section{International Journal of Applied Sciences and Smart Technologies}

Volume 3, Issue 2, pages 215-224

p-ISSN 2655-8564, e-ISSN 2685-9432

\section{Conclusion}

This study investigates the effect of parallelogram winglet vortex generator inside circular tube heat exchanger. Plain circular tube heat exchanger was used in this study as the base case to be compared with the use of vortex generator deployed inside the tube with the configuration of leaned following the flow and leaned against the flow. The conclusion of the study based on the results acquired are:

a. The use of Parallelogram winglet vortex generator can increase heat transfer performance of plain tube heat exchanger using ammonia as the working fluid.

b. The use of against the flow configuration resulting in the increase of Nusselt number higher than the leaned following the flow configuration.

c. The use of leaned following the flow configuration can increase the Nusselt number ranging from $4.39 \%$ to $7.10 \%$ while the use of leaned against the flow configuration $21.04 \%$ to $25.36 \%$.

\section{References}

[1] Y. Xu, M. D. Islam, and N. Kharoua, "Numerical study of winglets vortex generator effects on thermal performance in a circular pipe," International Journal of Thermal Sciences, 112, 304-317, 2017.

[2] P. W. Deshmukh and R. P. Vedula, "Heat Transfer and Friction Factor Characteristics of Turbulent Flow Through A Circular Tube Fitted with Vortex Generator Inserts," International Journal of Heat and Mass Transfer, 79, 551-560, 2014.

[3] Y. Xu, M.D. Islam, and N. Kharoua, Experimental study of thermal performance and flow behaviour with winglet vortex generators in a circular tube, Applied Thermal Engineering, 135, 257-268, 2018.

[4] H. Liu, H. Li, Y. He, and Z. Chen, "Heat transfer and flow characteristics in a circular tube fitted with rectangular winglet vortex generators," International Journal of Heat and Mass Transfer, 126, 989-1006, 2018.

[5] Y. Lei, F. Zheng, C. Song, and Y. Lyu, "Improving The Thermal Hydraulic Performance of A Circular Tube by using Punched Delta-Winglet Vortex 


\section{International Journal of Applied Sciences and Smart Technologies}

Volume 3, Issue 2, pages 215-224

p-ISSN 2655-8564, e-ISSN 2685-9432

Generators," International Journal of Heat and Mass Transfer, 111, 299-311, 2017.

[6] C. Zhai, M. D. Islam, R. Simmons, and I. Barsoum, "Heat Transfer Augmentation in A Circular Tube with Delta Winglet Vortex Generator Pairs," International Journal of Thermal Sciences, 140 , 480-490, 2019.

[7] Z. Sun, K. Zhang, W. Li, Q. Chen, and N. Zheng, "Investigations of the turbulent thermal-hydraulic performance in circular heat exchanger tubes with multiple rectangular winglet vortex generators," Applied Thermal Engineering, 168, 114838, 2020 .

[8] S. Pourhedayat, S. M. Pesteei, H. E. Ghalinghie, M. Hashemian, and M. A. Ashraf, "Thermal-exergetic behavior of triangular vortex generators through the cylindrical tubes,” International Journal of Heat and Mass Transfer, 151, 119406, 2020.

[9] J. F. Zhang, L. Jia, W. W. Yang, J. Taler, and P. Oclon, "Numerical analysis and parametric optimization on flow and heat transfer of a microchannel with longitudinal vortex generators," International Journal of Thermal Sciences, 141, 211-221, 2019.

[10] Y. Zhang, C. Kang, H. Zhao, and S. Teng, "Effects of in-line configuration of drag-type hydrokinetic rotors on inter-rotor flow pattern and rotor performance," Energy Conversion and Management, 196, 44-55, 2019. 